\title{
Human Quarantine vis-a-vis the State of Exception
}

Santos IAD ${ }^{1}$, Palhares $\mathrm{D}^{2 *}$ and Nascimento WFD
Department of Bioethics, University Hospital of Brasilia, Brazil

*Corresponding author: Dario Palhares, Department of Bioethics, University Hospital of Brasilia, SQS 416 bloco i apto 204, Asa Sul, CEP 70299-090, Brazil, Email: dariompm@unb.br

\section{Review Article}

Volume 3 Issue 2

Received Date: April 14, 2020

Published Date: April 30, 2020

DOI: $10.23880 /$ abca- 16000118

\section{Abstract}

Theoretically, human quarantine aims to control an epidemic outbreak, but evidences have pointed to be inefficient. The present paper tried to approach the question using the lens of the State of Exception. The microbes are ethereal, invisible, and ubiquitous; they easily create panic and evoke the fear of death in the population. The tools of bio power have succeeded in planting the basis of a State of Exception. Inquisition comes back: it is not needed any proof; a simple suspicion is enough to arrest a given person. Human quarantine needs deeper scientific studies to get legitimacy. Several quarantine measures are decided by non-medical professionals who bureaucratically adopt protocols from the State organs. In conclusion, human quarantine should be substituted by measures that are scientifically based. The sick persons deserve treatment and mercifulness and must be respected in their autonomy.

Keywords: Epidemiology; Protection; Infectious Diseases; Public Health; Bio Power

\section{Introduction}

To the scope of the present discussion, human quarantine is defined as the period of reclusion imposed to sick people or to asymptomatic people suspected of bearing epidemic infectious diseases (often because of having had previous contact with a patient), independently of where the person stays recluse, if at home or if in a hospital. That is, our scope is about the ethical questions underlying human quarantine as a measure for controlling an epidemic outbreak.

Such definition is important, since human quarantine practices have been carried out since thousands of years, eventually being cited in the Christian Bible. Also, in the literature, there may be distinction between 'quarantine' and 'isolation', such as of Roberts [1], who has defined quarantine as the intra-hospital reclusion of patients and isolation as the home confinement of people. Anyway, the intra-hospital isolation of severely ill patients for the protection of the other inpatients does not figure as object of the present work because, being a clinical measure, it does not impact the whole society.
Theoretically, human quarantine aims to control an epidemic outbreak. Concretely, it is presented as three basic policies:

a) Prohibiting the arrival in national territories of people who have manifested symptoms of a given disease.

b) Prohibiting the arrival of persons who had contact in confined places (buses, ships, airplanes) with other persons manifesting a given disease.

c) Impediment of free circulation (domiciliary or hospital arrest) of people who have manifested determined symptoms and/or have contact with people bearing some diseases [2].

Taylor E, et al. [3] considers quarantine as an effective and necessary means to control serious infectous diseases, being the most active measure a society can do in its defense. This way, Cole J, et al. [4] and Firman J, et al. [5] have stated that human quarantine, being a public health measure, is ethically justifiable as the sanitary interests of a whole community prevails over personal guarantees and interests of free locomotion and Sutton M, et al. [6] states on the need of a socially acceptable balance between societal protection 
and least restrictive impingements on individual freedom.

However, not all countries follow such paradigm. Bordonada RM, et al. [7], regarding the 2016 outbreak of Ebola in West Africa, denounces that quarantine measures were implemented in Spain at the margins of any scientific basis. They criticize the media in disproportionate and sensationalist coverage, contributing to widespread panic. The first measure regarding Spanish aid caretakers who got sick from Ebola was to treat them as inpatients in a tertiary hospital. But as news provoked panic in the population, the aggressiveness reached to an irrational point where a group of immigrants was totally kept in isolation for 18 hours in Aluche (a neighborhood of Madrid) without receiving any sustenance [7].

So, clearly the health systems are not facing merely a debate between individual rights and societal protection, but something complex, poorly studied and understood. Basically, we should have a bioethical discussion regarding the limits of human quarantine, such as to guarantee health and basic necessities of the people who are kept under those measures.

Moreover, it is needed to verify if human quarantine is an efficient method in the contention of an outbreak. Existing literature does not support this viewpoint. On the contrary, it is evidenced that instead of altering or blocking the onset of an outbreak quarantine measures actually worsen the overall health indicators of persons/populations subjected to this system $[8,9]$.

So, the bioethical discussion has reached another level which asks for a justification why human quarantine remains in worldwide laws. Since the answer is complex, as it involves multiple aspects, the present paper tries to approach this question using the lens of the State of Exception.

\section{Brief History of Human Quarantine}

The word quarantine originated from the Latin word 'quadraginata', the Italian word 'quaranta', and the French word 'quarantaine' [10]. It is attributed to a period of 40 days of isolation imposed on passengers and loads from ships by port authorities if they suspect that there were persons with infectious diseases. The quarantined persons were kept either in the ship or in a lazaretto (a quarantine hospital).

The significance of ' 40 days' has historical origins in Ancient China where, in the beginning of vaccination against smallpox, it was observed that the scars extracted from the patients remained infectious for about 40 days in winter and only 20 days in summer $[11,12]$. This empirical observation is related to several cultural rites with the aim of purification and/or stopping the propagation of infectious diseases [13].

During the middle Ages in Europe, quarantine practices were notorious in the initial years of the Black Plague epidemics [14]; the patients were isolated in churches and dungeons until death. As Plague spread out, quarantine became impossible [15], and trader ships with a slightest sign of Plague onboard used to drift. In this context, Mediterranean cities started a strong control over the ports in which the crew and passengers were confined in quarantine islands before having authorization to arrive $[16,17]$.

Since the XIX Century, quarantine has been adopted as a custom law by several nations together with laws on sanitation and with travels between continents in means of transportation each time faster.

Since 1851, several international meetings called "quarantine, health and sanitary conferences" have been conducted [18]. The first one was held in Paris. The key words of these conferences include sanitation, diseases, and epidemics. These conferences had spoken about laws and protocols for controlling epidemics, means of prevention, personal hygiene, etc. The resolutions had established international laws of quarantine against cholera, yellow fever, and other diseases in regard to travels and migration [19].

Two months after establishment of the United Nations, the First World Health Assembly was conducted in 1946. In this assembly, a committee was formed with specialists in epidemiology and international quarantine to revise the existing conventions and gather them in a single document. In 1950, this committee finally sent a project of the International Health Regulation to all countries for final observations. Finally in 1951, the text was approved as the Regulation $\mathrm{n}^{\circ} 2$ of the World Health Organization at the Fourth World Health Assembly [20].

The risks of new epidemics were promptly accepted, and quarantine gained an international status as an efficient way of sanitary control. Since then, the sanitary control of persons and commodities is considered as an important mark in modern international relationships.

\section{Epidemiological Inefficiency of Quarantine}

Since public health measures present a wide scope and a deep impact, research concerning this particular area is of prime importance. So, to rank the state of art of a given medical/epidemiological context, several classification systems have been created and adopted; however, the classification of the Oxford Centre for Evidence-Based Medicine, which was reviewed in 2009, has reached the 
overall acceptance. In this system, the recommendations are classified from A to D (A, B, C, D), where D is the weakest level of evidence and $A$ is the strongest [21]. Often, D studies are the opinions of specialists or basic experiences in animal models; C studies are series of cases; B includes case-control studies and/or prospective cohort studies or reviews based on them; and A includes clinical essays and systematic reviews or meta-analysis of clinical essays [22].

Moreover, parallel to the rank of evidence, basic epidemiologic parameters must also be continuously monitored to address whether a given health measure should be continued or interrupted. Particularly, the data of absolute risk reduction or aggravation and the necessary number to treat are parameters that must be taken into consideration while taking a public health decision [23].

In this context, the conclusion drawn by Cole J, et al. [4] and also Giubilini A, et al. [24], regarding the bioethical validity of human quarantine without any consolidated data is surprising. In other words, there are no studies that validate human quarantine under the scientific-epidemiologic scrutiny. There may be only a few studies that answer the following questions statistically: 'how many persons must be put in quarantine to avoid spreading the disease?' 'How many ships must be prohibited to arrive to protect a person to show the disease inside the national land?'.

Firman J, et al. [5] has worked on a mathematical model of an epidemic course, same as Day T, et al. [25]. This is a statement that is not even ranked: can a hypothesis become evidence in public health just because it is expressed in difficult and hermetical mathematical language? Basically, the authors have described quarantine as a morally accepted or rejected measure, as if the efficiency was obvious and selfevident. Moreover, those models point out that quarantine measures, to be really efficient, must be appropriate and without any leakage, that is, a single patient who somehow escapes from the barrier would break the whole policial structure created to block the epidemic chain.

However, literature has presented several works that point out the inefficiency of quarantine. As D-evidence studies, Santos MS, et al. [26] and also Rebelo F, et al. [27] have reminded that, in 1910, several reports from hygienists clearly reveal that the quarantine of all ships in the lazaretto of Big Island had never been an impediment for sick people arriving in Brazil, and even less such measure was related to the recurrence of epidemics that infested Rio de Janeiro.

As C-evidence studies, measures against the overall population that often hit the poorest in a stronger way had been applied during the epidemics of Spanish Flu in 1918 in Sao Paulo [28]. Copying the French model, the population had been prohibited of going out to the streets, which subsequently resulted in starvation and eventual deaths. Such effect was stronger than the infection to be controlled. Even after taking such measures, the governor of Sao Paulo got sick by that flu, and the recently elected president Rodrigues Alves died, clearly showing the inefficiency of human quarantine [28].

As B-evidence studies, early in 1910, Roberts J, et al. [1] had compared quarantine and isolation of children with diphtheria, concluding that those measures were totally inefficient in preventing new cases; home isolation was significantly related to higher mortality, and the most helpful measure was to treat the patient in hospital. Indeed, Kucharski A, et al. [29] has shown that the addition of beds to treat Ebola patients is the main measure that has positive impact against the recent epidemics.

Jones EW, et al. [30] has reviewed the data about the Spanish Flu in Canada that had not imposed any restriction to foreigners. The author has concluded that human quarantine shows more harmful effects, and it is not a good measure to control or reduce epidemics. Bondy $S$, et al. [31] have published an estimation report, which shows that at least 7,5 persons should be put into quarantine to prevent a new case; however, the authors have stated that the statistical analysis of the data was weak; so, this proportion would be just an initial approach. Nonetheless, Barbera J, et al. [32] has stated that human quarantine is not a primary measure in public health. It is a drastic measure that, in the most favorable scenario, should be implemented for a short duration only to small populations with well-defined territories. That is, the recent positions of Taylor E, et al. [3] and of Sutton M, et al. [6] are still biased and based merely on ancient beliefs, without any solid study validating quarantine as an efficient method.

Moreover, existing literature has clearly revealed that human quarantine is an expensive measure that cannot reduce or modify the natural cycle of an epidemic. Such results are not a surprise, since the discovery of microorganisms has revealed the existence of health carriers, mild to severe degrees of manifestation, and incubation period of an infection. So, a person with severe symptoms of a disease is likely to make contact with other patients unknowingly and already spreads out the microbe.

Interestingly, diarrhea and yellow fever are subjected to quarantine, but they are not transmitted by person-toperson contact. Diarrhea spreads out in places that lack basic sewage; yellow fever is a zoonosis (it is present in the environment independently from human populations) transmitted by mosquitoes. 
Hence, there has not been found any article, any studying proving or showing that human quarantine blocks any epidemic outbreak neither that human quarantine is effective in preventing other people to get sick during an epidemic outbreak. The mathematical models argue that such failure would be due to 'innapropriately' or 'weakly' implemented quarantine, but even the studies on the recent quarantine measures during the Ebola epidemics, considered as 'appropriately controlled', showed that while the treatment of patients has epidemiologic impact, the human quarantine is at most indifferent, if not iatrogenic [29].

\section{The State of Exception-General Overview}

The term 'bio power' was published by Michel Foucault $\mathrm{M}$, et al. [33,34]. It is regarded as the genealogical regulation of bodies in the consolidation of the modern States [34]. The bio power rules the relations between knowledge and power, which is the social control over the individuals, starting over the body as workforce [35]. Such link has generated new shapes of the dominant practices, which treat individuals as manipulable objects in a way that even intimate personal behaviors can be guided by the State. Bio power and bio politics together with the consolidation of Law States have become stronger and clearer in the XIX Century inside a Law system. Such laws and of jurisdiction and administrative instances mediate the relationship of individuals among themselves as well as the relationships between individuals and the public power.

The bio power is related to the overall power of the State, which is basically the power of the medical knowledge that guides human behavior, human potential, and human finalities. In the reality of the State, the health system has been agglutinated by the economic order, becoming not only means of cure but also means of social control [33-35].

The notion of bio power allows us to conceptualize and contextualize the social and political tendencies of modernity. In this way, it is important to reflect about the desirable side of the power that maintains social cohesion. However, the other side of the coin is to keep in mind the imminent risk of an uncontrolled power, which appears as a blind and generalized dominance from the State agents who detain the knowledge by using rhetorical speeches that break the limits of ethics [36].

The constant, real risk of the appearance of totalitarian governors based on the modes of exception and emergency highlights the paradox inherent to the society of control, which is manifested coercively by the State in many social spheres. The emergency sometimes is not a real concrete happening, as it can be expressed as a generalized war, a virtual reality fed by media and social communication with utilitarian values raised in the bio power, in the administration of human life's $[8,9]$.

The Democratic State of Law is historically very recent and has developed in parallel to the expansion of science and technology, which has created extremely deadly weapons; however in contrast, it has also integrated worldwide societies in economically complimentary activities. A few decades ago, the war used to be a mean of a given society to gain capital; whereas, the war is nowadays an element of a great prejudice, as it breaks international productive chains. There is not a single State; there are many States. A State can only be defined facing other States in a mutual recognition of frontiers and areas of jurisdiction $[38,39]$.

Internally, the power of the States is legitimized due to their power-to-do [39]. When an external force threatens a society, the power of the State is enhanced. The definition of the State of Exception and State of Siege has its origins in the war. In 1791, the Constituent Assembly normalized this question in France [38]. According to which, the country or a city could be in the State of Peace, of normality; in State of War, when the civil authorities were totally subordinate to the military authorities, and the State of Siege. As the word says, the State of Siege means that the city/country is surrounded by the enemy; submitted to an imminent risk of invasion; and facing implosion of the whole social structure due to events like rapes, murders, destructions, and so on $[8,9,38,39]$. However, even with the evolution of the States and displacement of wars towards the frontiers, the alert button of State of Siege remains in the laws of the Democratic States. Not necessarily the enemy of a society is a foreign army. The State of Siege has been used to legitimate dictatorships in Latin America; it was the regimen used by Hitler to evoke the III Reich; it was used to fight workers' strikes; it was justified as the maximal cause for freeing the proletarians [39].

As Agamben G, et al. [38,39] has clarified, the State of Siege is not a new legal order but an implosion of the Democratic State and the reborn of an Absolutist State that has no day and no time to end. In the Absolutist States, the cause of existence of a society is embodied in the Leader. If the Leader reaches the position with the speech of gathering and protecting the society at the beginning, quickly the power degenerates so that the Leader sacrifices the country in the name of him. The Absolutist State is successful when the citizens/subjects are available to receive more than a bullet shot against the Leader, but a bullet shot by the Leader in the name of a greater Cause.

Legally, a person has rights to face the State. However, during the situations of Exception, a significant amount of population is reduced to the condition of bare life, which is 
the condition of a strict biological life that in more extreme situations a person can be killed, and the murder will not be considered as punishable by the State. So, under quarantine, the bare life is evident; the persons, mainly when categorized as 'sick' or as 'possible contact', lose many, if not all, of the basic, fundamental guarantees. From citizens of rights and duties they become walking dangers to be managed and controlled [34,35].

In the Democratic State, the society demands from the State administrative probity, as well a complex power-to-do that includes health, territorial organization, sponsor to arts, sports, and science/technology, and income redistribution. From the point of view of the Power, the citizens have become more abusive, less respectful to the Leader, and intolerant to the arbitrariness of the State. This way, sometimes the Democratic States use war devices to frighten the citizens and legitimate the absolute power via manipulation of the psychical phenomenon of in-groups. In-groups is manifested in a group of humans facing an external common threat that is able to bring an extreme union to the group, overcoming old frictions and differences. Facing the common threat, an individual who still remains disconnected to the group activity (the isolated, the marginal, the deviant, the discordant, and the ill) can be summarily destroyed by the furious masses. The common threat excludes debates, divergent thinking, and different attitude $[33,38]$.

Situations of Exception have been carried out sometimes to make the engines of the Power work. As a machine that rusts if stopped for a long time, the structures of the Power may fail if they are not periodically exercised, at least in a simulated mode or lighter mode compared to a true war $[8,39]$.

\section{Human Quarantine has Been Kept in the Legal Orders because it is A Strong Tool for the Implementation of a State of Exception.}

The microbes are something that the Power of State considers strategically. They are ethereal, invisible, ubiquitous, and as well as they are related to the main powers of the State-the power of health-and easily create panic and evoke the fear of death in the population. The structures of public health are naturally infiltrated and accepted by the citizens. The citizens are unlikely to freely open their doors to a military uniform, but promptly and widely open them to a health care professional who harvests detailed intimate data. So, the tools of bio power succeed with a great efficiency in planting the basis of a State of Exception. In worldwide experiences, the citizens do not tolerate a State of Exception due to strikes. Perhaps, they can be frightened for a few time due to the news of a terrorist attack; but, surely they uncritically accept the State of Exception if the enemy is a deadly microbe $[8,9]$.

The fear of the lethal microbe sustains a generalized panic, which leads to a total submission to the hegemonic propaganda from media that strategically silences or mocks any in submission or questions of their proposals of restriction of personal freedom. The lethal microbe legitimates the practices of either personal or group exclusion of everyone who might be considered malefic by the Power. Rarely, the economically powerful persons are submitted to quarantine; this is clearly a practice against poor patients. It does not need any proof or any clinical sign; a simple contact or a simple suspicion is enough to arrest a given person; above all, the person can even be killed in the name of 'public security' $[8,9]$.

In this point, India can illustrate those aspects of excess of the State regarding infectious diseases. Juran L, et al. [40] describes the historical military-style operations in India at the time of eradication of smallpox via forced vaccination: "the mission was search and destroys: each case was treated as an absolute emergency, surveillance-containment was the method and guards were deployed for manpower". Battacharya $S$, et al. [41] compares all those civil wars against smallpox to the modern goal of eradication of polio. Although India has not eradicated polio and faces several vaccination problems, the annual incidence of wild polio has been around 470 cases. It could be zeroed, but it clearly shows that without any aggressiveness, any imprisonment, any forced quarantine it is possible to control an infectious disease down to a small number of cases, considering the huge Indian population.

The State of Exception is a degeneracy of the Democratic State of Law. The Democratic States of Law does not have an unlimited authorization to impose treatments and/or arrest patients. It is even less for those who merely have contact with patients. These limits are of two natures:

a) Juridical, since democracy consists, among several aspects, in limiting the State [38].

b) Scientific, since the studies of the complex question of human quarantine have shown little efficiency and also that the coercive practices tend to be iatrogenicdeteriorating overall health of the quarantined people.

Human quarantine needs deeper scientific studies in order to get legitimacy. It is important to address what is the outcome of submitting a person to quarantine; what is the real epidemiological impact of these situations; what statistical tools can show if a given outbreak ended naturally by itself or as a result of quarantine; how the structures of hospitals and clinics work during quarantine measures; and several other questions that remain unanswered up to now. But, as denounced by Devnani M, et al. [42], sometimes 
health authorities have isolated travelers in situations that are clearly against the WHO guidelines for human quarantine, showing that those measures are rather political than scientific [42].

In daily medical practice, the hospitalization of a patient is the last resource inside a network of attention to overall infectious diseases. Shockingly, several quarantine practices are adopted and/or decided by non-medical professionals who often occupy civil jobs of the State. In other words, it has become a bureaucratically adopted protocol by State corporations that have power but not knowledge. The Public Health must not be omitted; it should never show ambiguities regarding the complex problem of fighting against epidemics.

In the state of art, human quarantine remains in the legal orders as one of the many embryos to the establishment of a State of Exception. Human quarantine represents the side of bio power that supports offensive practices against the fundaments of the Democratic State of Law; it is a way for a given State to implement situations of Exception with maximal popular acceptance.

\section{Conclusion}

In conclusion, due to inconsistencies regarding the real extent of the effectiveness of human quarantine together the data showing undesirable side effects, its plain and a critical acceptance in the international legal norm should at least be reviewed, perhaps being banned, unless strong and welldesigned epidemiological studies prove its relevance. The sick persons deserve treatment and mercifulness [43].

\section{Acknowledgement}

We thank the Indian company Content Concepts for English corrections.

\section{References}

1. Roberts J (2011) Quarantine or Isolation in Diphtheria? Journal of the American Public Health Association 1(5): 353-358.

2. Cetron M, Landwirth J (2005) Public Health and Ethical Considerations in Planning for Quarantine. Yale J Biol Med 78(5): 329-334.

3. Taylor E (2017) Quarantine: erring in the side of public safety. Journal of Homeland Security and Emergency Management 14(1): 20160081.

4. Cole J (2015) Federal and State Quarantine Isolation and Authority. Current Politics and Economics of the United States, Canada and Mexico 17(2): 273-287.
5. Firman J, Williams S, Baggoley C (2016) From Plague to MERS: Coordinating Australia's Response to Emerging Infectious Diseases. Public Health Research and Practice 26(5): e2651654.

6. Sutton M (2017) Forced quarantine and isolation: does the law adequately balance individual rights and societal protection?. University of La Verne Law Review 39: 98142.

7. Royo BM, Lopez F (2016) Ethical considerations surrounding the response to Ebola: the Spanish experience. BMC Medical Ethics 17: 49-58.

8. Santos I, Nascimento W (2014) As Medidas de Quarentena Humana na Saúde Pública: Aspectos Bioéticos. Bioethikos. Centro Universitário São Camilo 8(2): 174-185.

9. Santos I, Nascimento W (2017) Human quarantine and state of exception. Curitiba: Editora Prismas, pp: 126.

10. Jewell W (1985) Historical Sketches of Quarantine. $2^{\text {nd }}$ (Edn.), Philadelphia, pp: 32.

11. Kilwein JH (1995) Some Historical Comments on Quarantine: Part One. Journal of Clinical Pharmacy and Therapeutics 20(4): 185-187.

12. Kilwein JH (1995) Some Historical Comments on Quarantine: Part Two. Journal of Clinical Pharmacy and Therapeutics 20(5): 249-252.

13. Porto A, Ponte CF (2003) Vaccines and campaigns: images with a story to tell. History, Sciences, HealthManguinhos 10(S2): 725-742.

14. Mackowiak P, Sehdev OS (2002) The Origin of Quarantine. Clinical Infectious Diseases 35(9): 1071-1072.

15. Maglen K (2002) The First Line of Defense: British Quarantine and the Port Sanitary Authorities in the Nineteenth Century. Social History of Medicine 15(3): 413-428.

16. McDonald JC (1951) The history of Quarantine in Britain during the $19^{\text {th }}$ Century. Bull Hist Med 25(1): 22-44.

17. Rebelo F, Chor Maio M, Hochman G O (2011) Princípio do Fim: o “Torna Viagem”, a Imigração e a Saúde Pública no Porto do Rio de Janeiro em Tempos de Cólera. Estudos Históricos 24(47): 69-87.

18. Ersoy N, Gungor Y, Akpinar A (2011) International Sanitary Conferences from the Ottoman Perspective (1851-1938). Hygiea Internationalis 10(1): 53-79. 
19. Chiffoleau S (2011) Les Pèlerins de La Mecque, les Germes et la Communauté Internationale. Médecine Sciences 27(12): 1121-1126.

20. World Health Assembly, 4. (1952) International Sanitary Regulations: Proceedings of the Special Committee and of the Fourth World Health Assembly on WHO Regulations no. 2. World Health Organization, pp: 443.

21. Medeiros L, Stein A (2002) Evidence Levels and Degrees of Recommendation of the Evidence-based Medicine. Revista AMRIGS 46(1-2): 43-46.

22. (2009) Oxford Centre for Evidence-based Medicine. Levels of Evidence.

23. Coutinho ESF, Cunha GM (2005) Basic Concepts in Epidemiology and Statistics for Reading Controlled Clinical Trials. Braz J Psychiatry 27(2): 146-151.

24. Giubilini A, Douglas T, Maslen H, Savulescu J (2018) Quarantine, Isolation and the Duty of Easy Rescue in Public Health. Dev World Bioeth 18(2): 182-189.

25. Day T, Park A, Madras N, Gumel A, Wu J (2006) When is Quarantine a Useful Control Strategy for Emerging Infectious Diseases?. Am J Epidemiol 163(5): 479-485.

26. Santos MS (2007) Lazareto da Ilha Grande: Isolamento, Aprisionamento e Vigilância nas Áreas de Saúde e Política (1884-1942). Históiria, Ciências, Saúde Manguinhos 14(4): 1191-1196.

27. Rebelo F (2013) Entre o Carlo R. e o Orleannais: a Saúde Pública e a Profilaxia Marítima no Relato de dois Casos de Navios de Imigrantes no Porto do Rio de Janeiro, 1893-1907. História, Ciências, Saúde Manguinhos 20(3): 765-796.

28. Bertolli Filho C (1986) Epidemic and Society: the Spanish Flu in the Municipality of São Paulo [M Sci Dissertation]. Sao Paulo: University of Sao Paulo, Brazil.

29. Kucharski A, Camacho A, Flasche S, Glover R, Edmunds J, et al. (2015) Measuring the Impact of Ebola Control Measures in Sierra Leone. Proc Natl Acad Sci 112(46): 14366-14371.

30. Jones EW (2005) "Co-operation in All Human Endeavour": Quarantine and Immigrant Disease Vectors in the 1918-1919 Influenza Pandemic in Winnipeg. Can Bull Med Hist 22(1): 57-82.

31. Bondy S, Russel M, Lafleche J, Rea E (2009) Quantifying the impact of community quarantine on SARS transmission in Ontario: estimation of secondary case count difference and number needed to quarantine. BMC Public Health 9: 488.

32. Barbera J, Macintyre A, Gostin L, Inglesby T, O'Toole T, et al. (2001) Large Scale-Quarantine Following Biological Terrorism in the United States: Scientific Examination, Logistic and Legal Limits, and Possible Consequences. JAMA 286(21): 2711-2717.

33. Foucault M (1981) The order of discourse. In: Young, RJC (Ed.) Unitying the Text. A Post-Structuralist Reader Boston: Routledge and Kegan Paul, pp: 48-78.

34. Foucault M, Davidson A, Burchell G (2008) The Birth of Biopolitics. Lectures at the College de France 19781979. New York: Palgrave McMillan, pp: 340.

35. Foucault M (2009) Security, Territory, Population. Lectures at the Collège de France 1977-1978. New York: Palgrave McMillan, pp: 409.

36. Palhares D, Santos I (2012) Pre-employment medical testing in Brazil: ethical challenges. Indian J Medi Ethics 9(4): 266-268.

37. Palhares D, Santos I, Cunha A| (2016) Racial quotas visa-vis the State of Exception. Revista Latinoamericana de Bioética 17(1): 150-167.

38. Agamben G (2005) State of Exception. Chicago: The University of Chicago Press, pp: 95.

39. Agamben G (1998) Homo sacer: Sovereign Power and Bare Life. Stanford: Stanford University Press: 228.

40. Juran L, Trivedi J, Kolivras N (2017) Considering the "public" in public health: popular resistance to the smallpox eradication programme in India. Indian J Med Ethics 2(2): 104-111.

41. Battacharya S, Dasgupta R (2011) Smallpox and polio eradication in India: comparative stories and lessons for contemporary policy. Ciên Saúde Colet 16(2): 433-444.

42. Devnani M, Guo Y (2015) Isolation of an individual already treated for Ebola: has India gone too far? Indian J Med Ethics 12(4): 246-248.

43. Palhares D, Cunha A (2013) Ethical approach to aggressive situations involving dependent patients and doctors. Latin American Journal of Bioethics 13(1): 7479.

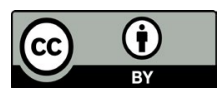

Palhares D, et al. Human Quarantine vis-a-vis the State of Exception. Ann Bioethics Clin App 2020, 3(2): 000118.

Copyright $($ C Palhares D, et al. 